\title{
Light Rail Transit System Energy Flow Analysis for the Case of Addis Ababa City: For the Application of Regenerative Energy and Energy Storage
}

Asegid Kebede ( $\square$ assegidjesus@gmail.com )

AAiT: Addis Ababa Institute of Technology https://orcid.org/0000-0002-5831-936X

Getachew Biru Worku

AAiT: Addis Ababa Institute of Technology

\section{Research Article}

Keywords: Energy flow, energy efficiency, regenerative braking, energy storage, light rail transit

Posted Date: June 3rd, 2021

DOl: https://doi.org/10.21203/rs.3.rs-547025/v1

License: (c) (1) This work is licensed under a Creative Commons Attribution 4.0 International License.

Read Full License 


\title{
Light Rail Transit System Energy Flow Analysis for the Case of Addis Ababa City: For the Application of Regenerative Energy and Energy Storage
}

\author{
Asegid Belay Kebede ${ }^{1}$, Getachew Biru Worku² \\ ${ }^{1}$ African Railway Centre of Excellence, Addis Ababa Institute of Technology, Addis Ababa, Ethiopia. \\ ${ }^{2}$ Electrical and Computer Engineering, Addis Ababa Institute of Technology, Addis Ababa, Ethiopia. \\ Assegidjesus@gmail.com
}

\begin{abstract}
Significant amounts of energy can be saved by installing energy storage on an electrified transit system allowing energy from braking to be captured. The amount of energy saved is dependent on the amount of energy transferred during braking which relies on the drive cycle and the vehicle parameters. Additional energy is saved through a lower overall energy requirement of train, which results in a reduction in traction supply losses. The overall benefit can be determined by analyzing the energy flow through components in an electrified transit system and hence determining the change in energy dissipations when energy storage is installed. In this paper, electrified transit system energy flows are analyzed for the implementation of energy storage system on board on Addis Ababa light rail transit. The methodology used assesses energy flows in the traction system, establishing where energy is dissipated. The analysis is performed for a specified drive cycle. Finally, the analysis showed that $36 \%$ of traction energy could be saved through the implementation of energy storage on the Addis Ababa light rail transit.
\end{abstract}

Keywords: Energy flow, energy efficiency, regenerative braking, energy storage, light rail transit

\section{Introduction}

Rising energy prices and the concern of depleting oil resources, and the unsustainable use of the world's resources is turning attention to alternative, cheaper transportation means which are less reliant on oil [1]. Commercial opportunities have arisen as a result. An opportunity has also arisen for the public transport sector; electrified mass transit systems have an opportunity to stake a claim in a changing market place.

Global warming concerns, particularly the political requirement to meet the Kyoto protocol [2] Emission quotas and the congestion of transportation corridors creates a need to shift to potentially more efficient transport solutions, including railways. Electrified transit 
systems, including light transit system provide a suitable form of alternative transportation for larger cities and can often provide a quicker mode of transportation around congested cities like Addis Ababa. It also offer an environmental benefit, generally consuming less energy per passenger kilometer and having a smaller contribution to greenhouse gas emissions compared to other transport modes. In addition, it also remove the pollution source from the point of use; potentially improve air quality levels within highly populated urban areas.

To provide the required alternative transportation, there is a requirement to improve the performance and capacity of electrified transit systems. To maintain the healthy environmental status of electrified transit systems and for the operation to continue to operate economically, these improvements must incorporate energy efficiency gains. Hence, any solutions which can improve performance, capacity and efficiency will assist in reducing greenhouse gas emissions and provide opportunities for commercial exploitation, increased revenues from additional passengers and savings from reduced energy costs.

The European union commissioned study [3] identifies 12 potential areas, which can achieve efficiency improvements in railway systems, weight reduction, reduction of air resistance, optimization of space utilization, improvements in electric traction components, efficiency gains in diesel traction technology, recovery of braking energy, reduction in energy consumption of comfort functions, energy efficient driving, traffic flow management, improvement of occupancy rates, energy meters and management and organization.

All these areas can be investigated to achieve energy efficiency improvements. It is also essential to consider the interactions between the different areas, particularly when efficiency gains are achieved by installing components which increase the weight of electric vehicles and affect space utilization. It is also vital that in improving efficiency performance is not compromised, hence maintaining the attraction to potential customers.

Research undertaken by the International Union of Railways [4] describes where electricity is dissipated in the rail industry. The result consists of an analysis of energy movements into and out of trains as shown in fig.1, taking into account losses or drops in the traction and traction mechanisms and of the transfer of energy to mechanical energy to overcome friction. The energy usage of hybrid electric train is analyzed using a similar method. Hence, energy flow assessments are an important way to analyze energy use.

In this research paper the energy flows of a train on an electrified transit system are analyzed. The concepts described here in this paper form a basis of the system modelling for the overall traction network (which is not the focus of this paper). The system modelling is used to analyze energy flows in electrified transit systems, allowing potentially energy saving techniques, such as energy storage installation to be assessed. 


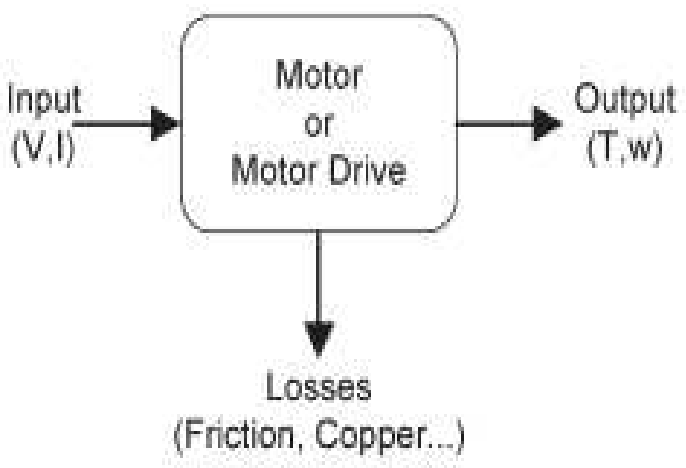

Fig.1 Energy flow block diagram

\section{Energy flow in light rail transit}

An electric transit vehicle converts electrical energy into kinetic and potential energy. Energy is dissipated overcoming frictional forces and in braking.

Energy is also dissipated through other mechanisms, including driveline losses and to power auxiliary loads. The electrical energy is transmitted from a local distribution network, through a traction substation, and the traction supply system. These stages also have energy losses. Fig. 2 shows a more comprehensive representation of energy flows in an electrified transit system, including loss mechanisms. This paper considers the energy flow through each sub system identified in Fig. 2 determine the overall energy dissipation [5].

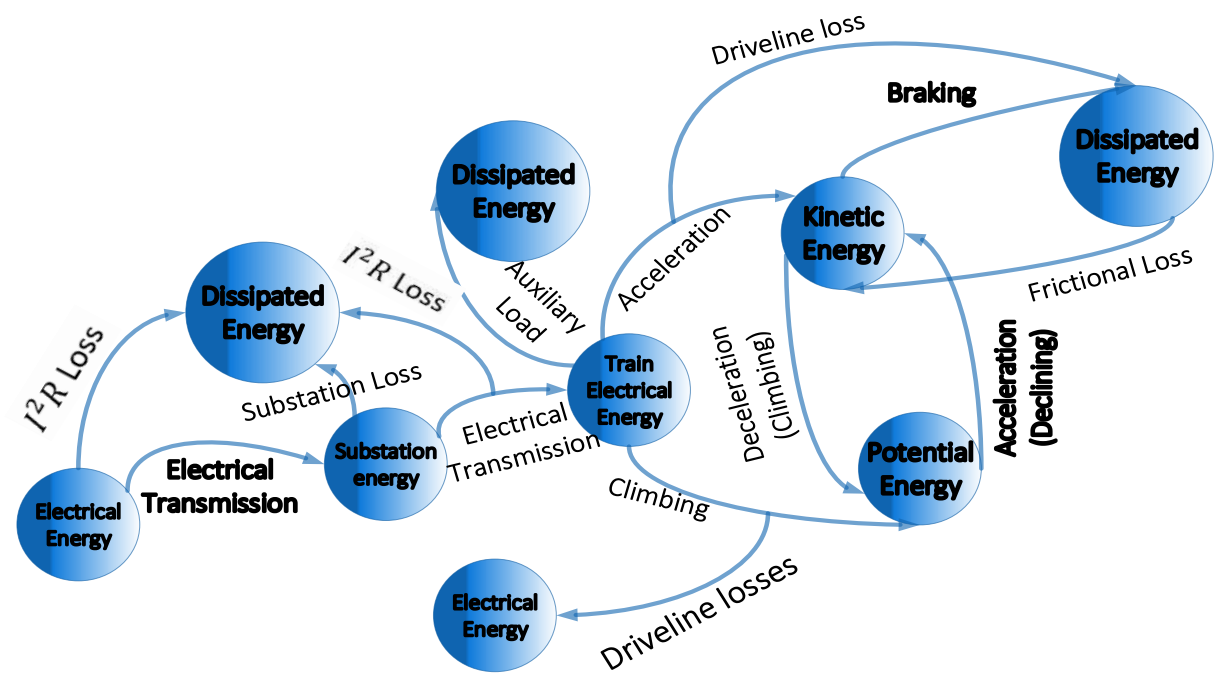

Fig.2 Electrified Transit System Energy Flow Diagram 


\subsection{Tractive Resistance}

Energy is used to counteract frictional forces in all traction applications. Davis [6] defines the traction resistance as a quadratic function of vehicle speed.

$$
F_{R}(t)=a+b v+c v^{2}
$$

If a vehicle velocity is treated as time, $v(t)$ can be defined as a resistive force in terms of time $F_{R}(t)$.

$$
F_{R}(t)=a+b v(t)+c v^{2}(t)
$$

The Power, $P_{R}(t)$ dissipated by the train to overcome a frictional force is the product of force and speed,

$$
P_{R}(t)=F_{R}(t) \cdot v(t)
$$

Then using (2) and (3)

$$
P_{R}(t)=a v(t)+b v(t)^{2}+c v(t)^{3}
$$

With respect to time, this can be integrated to calculate the energy losses caused by frictional forces.

$$
E_{R}(t)=\int_{t_{0}}^{t} a v(t)+b v(t)^{2}+c v(t)^{3} d t
$$

\subsection{The Driveline}

The light rail vehicle transforms electrical energy from the traction supply grid to kinetic energy. The conversion can be divided into several phases; Power electronic converter, electrical conduction, mechanical transmission and traction motor, all of these conversion processes have loss mechanisms as shown in fig. 3 .

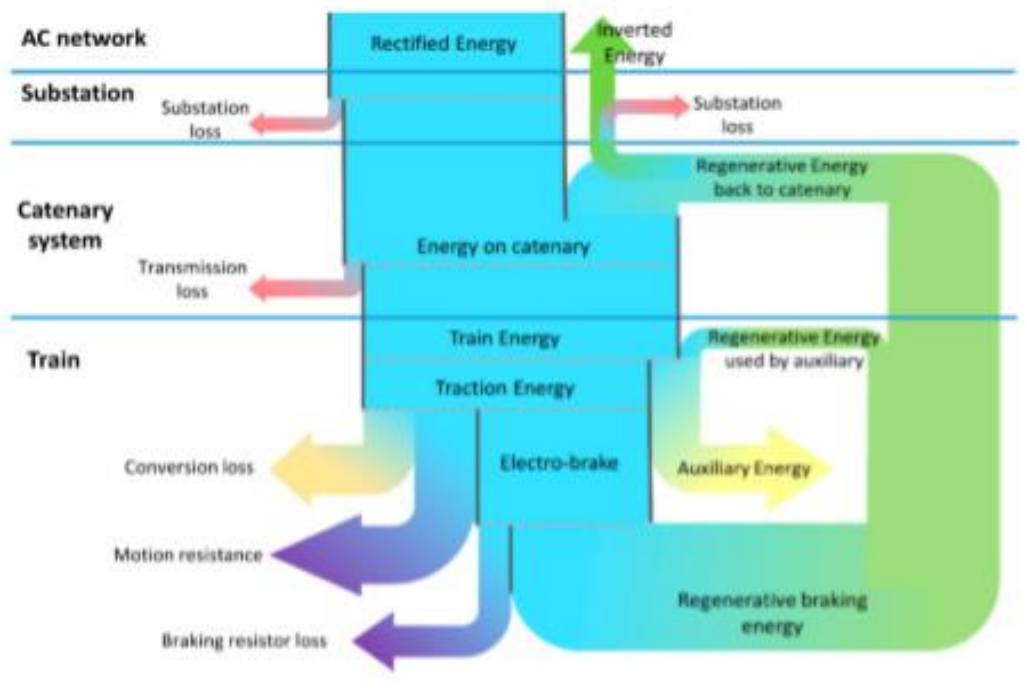

Fig.3 Energy flow block diagram of Electric Vehicle [5] 


\subsubsection{Train Electrical Conductors}

Electric energy is transported by electric conductors from the pantograph to the electronic power converter, which dissipates heat energy. The cable lengths in the train are usually short and the resistance levels are low, which can be considered as insignificant transmission losses inside the vehicle.

\subsubsection{Power Conditioner}

In order to achieve the necessary torque, the supply of electrical power is controlled by means of power electronic converters. Many new train use induction motors powered by inverter. Inverters transform a DC supply to the VVVF (three-phase variable voltage frequency) supply. Modern inverter consists of six switches (IGBTs with anti-parallel diodes) as shown in fig. 4. The switches are working to provide the appropriate frequency and voltage for a three-phase AC output.

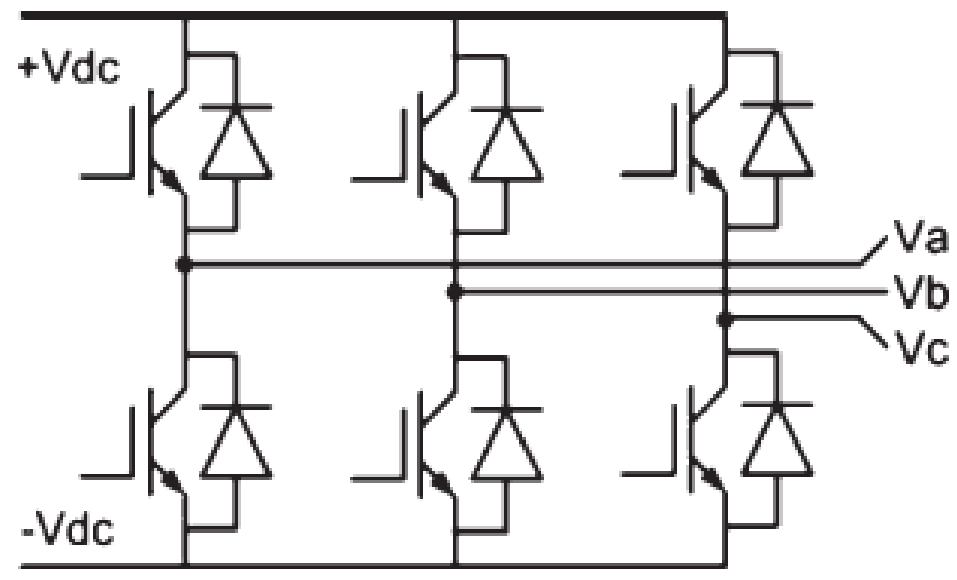

Fig. 4 Inverter Circuit Diagram

$$
P_{\text {inverter-leg-losses }}=P_{\text {cond_D }}+P_{\text {cond_Q }}+P_{\text {switch_on_Q }}+P_{\text {switch_off } \_Q}
$$

$P_{\text {cond } \_D}=$ conduction losses in the diodes

$P_{\text {cond } \_Q}=$ conduction losess in the IGBTs

$P_{\text {Switch_on_Q }}=$ switch-on losses in the IGBTs

$P_{\text {switch_of } \_Q}=$ switch-off losses in the IGBTs

The diode conduction, $P_{\text {cond_D }}$ losses ca be described as

$$
P_{\text {cond_D }}=\frac{1}{T} \int_{0}^{T} V_{F}(t) i_{D}(t) d t
$$


Where $V_{F}(t)$ is the diode junction voltage and $i_{D}(t)$ is the diode current, when the diode conducts this equals the line motor current. $V_{F}(t)$ can be written as a function of the current as shown below,

$$
V_{F}(t)=V_{F o}+i(t) R_{D}
$$

The values for $V_{F o}$ and $R_{D}$ can be derived [7] from manufacturer's datasheets [8]. For a Siemens BSM75GB120 these values are $V_{F o}=$ $1.25 \mathrm{~V}$ and $R_{D}=7.71 \mathrm{~m} \Omega$. The IGBT conduction losses can be described as

$$
P_{\text {cond_Q }}=\frac{1}{T} \int_{0}^{T} V_{C E}(t) i_{F}(t) d t
$$

Where, $V_{C E}(t)$ is the IGBT junction voltage and $i_{F}(t)$ is the IGBT forward current, which equals the motor current, when the IGBT is conducting, $V_{C E}$ varies is a function of the current.

$$
V_{C E}(t)=V_{C E O}+i_{F}(t) R_{C E}(t)
$$

Where $V_{C E O}$ is $1.83 \mathrm{~V}$ and $R_{C E}$ is $17.33 \mathrm{~m} \Omega$ [8]. The switching losses, $E_{O n}$ and $E_{O F F}$ are a function of the IGBT forward current. Fig. 5 shows the switching losses for a Siemens device, BSM75GB120.

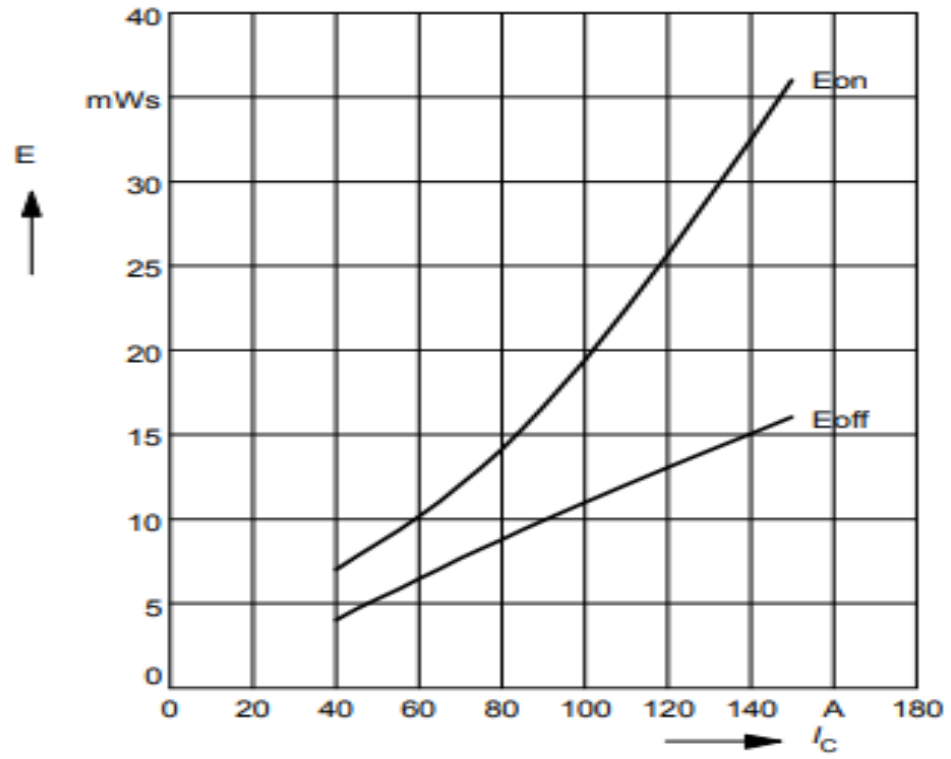

Fig.5 Switching losses against current for a Siemens BSM75GB120 device [8]

The energy loss over one cycle is the sum of the energy losses from each switching operation. The switching losses vary over the sinewave. To simplify the calculation, the RMS current is used to find the switch on and switch off losses from the graph. The switching power, $P_{\text {switching }}$ switching can be described as.

$$
P_{\text {switching }} \approx f_{\text {switching }}\left(E_{\text {On }}+E_{\text {OFF }}\right)
$$


The inverter loss energy is dissipated as heat, and therefore there is a cooling requirement. For the purpose of analyzing energy flows, the gate drive control circuit and cooling energy requirements are considered as auxiliary loads.

\subsection{The Induction Motor}

Induction motor loss mechanisms include ohmic losses, iron losses and frictional and windage losses [9]. The frictional and windage losses can be considered as part of the train's frictional loss. When the coefficients of the Davis equation are determined, the motor frictional and windage losses are included in the tractive resistance analysis. The ohmic losses that occur in the stator and rotor and are dependent on the stator and rotor resistances, $R_{s}$ and $R_{r}$ and stator and rotor RMS currents, $I_{s}$ and $I_{r}$.

$$
P_{\text {motor_ohmic }}=I_{s}^{2} R_{s}+I_{r}^{2} R_{r}
$$

There are three iron losses, $P_{\text {iron }}$, mechanisms, Hysteresis loss $P_{\text {hyst }}^{D}$, eddy current loss, $P_{\text {eddy }}^{D}$ and anomalous loss, $P_{\text {anom }}^{D}$. Iron losses can be simplified and related to the magnetization current.

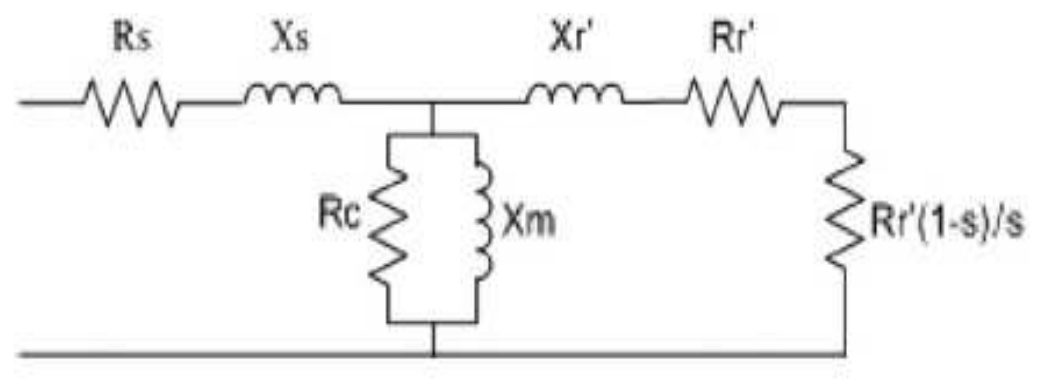

Fig.6 Induction Motor Equivalent Circuit [10]

An induction motor can be represented as a quasi-steady state equivalent circuit, Fig.6, using resistances to represent the three loss mechanisms, $R_{s}, R_{r}$ and $R_{c}$, representing the stator copper loss, the rotor copper loss and the iron loss respectively. The equivalent circuit can be evaluated to determine the motor losses.

\subsection{Mechanical Transmission}

The final stage of the drive is the mechanical transmission. The transmission consists of a gear box, usually made of up a driver gear on the motor shaft and a gear on the axle. Losses occur when one gear drives another [11]. The losses can be related to the coefficient of friction, $f^{\prime}$.

$$
P_{\text {gear_loss }}=P_{\text {mechanical }}\left[\frac{f^{\prime}}{2}\left(\beta_{a 1}^{2}+\beta_{r 1}^{2}\right)\right]
$$


Where $P_{\text {mechanical }}$ is the mechanical power transmitted, $\beta_{a 1}$ is the angle of approach for the driver gear and $\beta_{r 1}$ is the angle of recess for the driver gear. Frictional losses of the mechanical transmission, including bearing losses are considered as part of the frictional losses of the train. If frictional coefficients are determined using rundown tests, the effects of friction within the drive line are considered.

\subsection{Auxiliary loads}

Auxiliary loads are additional loads which do not produce tractive power. These include ventilation systems, braking systems, doors, control and monitoring systems, driver support facilities, battery charging and passenger comfort functions [12]. Ventilation is crucial to remove excess heat from traction and auxiliary equipment including power converters, motors and control equipment. The ventilation requirements are dependent on the size of the equipment and the heat energy produced, i.e. the losses. Most electric vehicles contain pneumatic systems to operate braking systems, doors and other equipment. A compressor is required to maintain the pneumatic system's pressure; energy is consumed by the compressor [13]. Control and monitoring systems play a vital role in the operation of electric traction vehicles. Control and monitoring systems control traction functions, drives, braking and passenger systems.

Driver support facilities include communication systems (e.g. radios), instrumentation, screen demisters, horns and lighting. Passenger comfort functions include lighting, heating, air conditioning, passenger information systems and CCTV. Auxiliary loads are supplied through auxiliary converters.

\subsection{Traction Power Supply System}

In electrified traction systems, vehicles are powered by electricity which is supplied from a local distribution network through a traction supply system. For the purpose of analyzing the energy flows of an electrified transit system, energy flows in the electricity supply system are considered from the point of connection to the local distribution system. The traction electrical supply system includes the

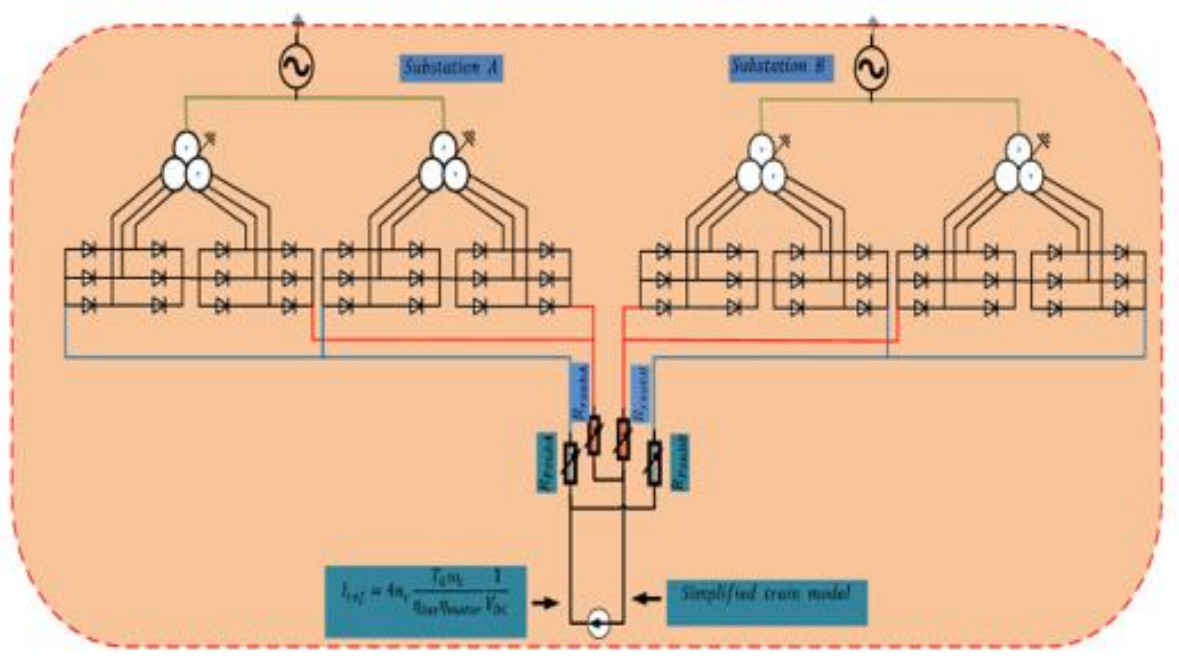


traction substations, the conductor system and a contact system. For DC systems, substations are located every few kilometers along the system (depending on the systems utilization and the voltage level). Substations consist of a transformer and a rectifier. Typically, 12pulse rectifiers are used to reduce harmonic distortion on the local distribution network. Fig.7 shows a traction substation layout.

Fig.7 DC Traction Substation Layout [14]

Transformer losses are divided into two categories, copper losses in the windings and core losses, $P_{C}$ due to hysteresis and eddy currents losses [15]. These loss mechanisms are similar to those described for induction motors.

$$
P_{\text {loss_transformer }}=3\left(I_{1}^{2} R_{1}+I_{2 a}^{2} R_{2 a}+I_{2 b}^{2} R_{2 b}\right)+P_{C}
$$

Where $R_{1} R_{2 a}$ and $R_{2 b}$ represent the resistance of the primary winding, and wye and delta windings of the secondary respectively. $I_{1}$ $I_{2 a}, I_{2 b}$ represent the primary and two secondary currents respectively. To simplify the equation an equivalent resistance can be used to relate the copper losses to the output current of the substation, $I_{\text {substation }}$

$$
P_{\text {loss_transformer }}=I_{\text {substation }}{ }^{2} R_{\text {eq_substation }}+P_{C}
$$

A 12 pulse rectifier consists of two full bridge rectifiers; each bridge contains of 6 diodes. At any instant four diodes are conducting, hence the losses of the rectifier can be determined by considering the losses in four diodes. Diode power losses occur due to the forward bias voltage $V_{d}$. The forward bias voltage varies with current, and can be described as

$$
V_{d}=V_{d o}+I R_{D}
$$

These values can be derived from manufacturers data sheets, for a diode rectifier $V_{d o}=0.81 \mathrm{~V}$ and $R_{D}=4.8 \mathrm{~m} \Omega,[8]$

$$
P_{\text {loss-diode }}(t)=V_{\text {do }} i_{\text {diode }}+R_{D} i_{\text {diode }}^{2}
$$

The four diodes that are conducting each conduct the rated current. The power loss in the rectifier can be described as,

$$
P_{\text {rectifier }}=4 V_{d} I_{\text {substation }}+4 R_{\text {on }} I_{\text {substation }}^{2}
$$

Where $I_{\text {substation }}$ is the substation output current. The overall loss of the substation is determined by adding the transformer losses to the rectifier losses and can be described as a quadratic function of the substation current.

$$
P_{\text {loss-sustation }}=I_{\text {substation }}{ }^{2}\left(R_{2 e q-\text { substation }}+4 R_{\text {on }}\right)+4 V_{d} I_{\text {sub_station }}+P_{C}
$$


The power loss can be related to the substation power, $P_{\text {substation }}$

$$
P_{\text {loss-sustation }}=\left(\frac{R_{\text {2eq-substation }}+4 R_{\text {on }}}{V^{2}}\right) P_{\text {substation }}+\frac{4 V_{d}}{V} P_{\text {sub_station }}+P_{C}
$$

This is integrated to calculate the energy dissipated.

$$
E_{\text {loss-sustation }}=\int\left(\left(\frac{R_{2 \text { eq-substation }}+4 R_{o n}}{V^{2}}\right) P_{\text {substation }}+\frac{4 V_{d}}{V} P_{\text {sub_station }}+P_{C}\right) d t
$$

\subsection{Traction Supply System}

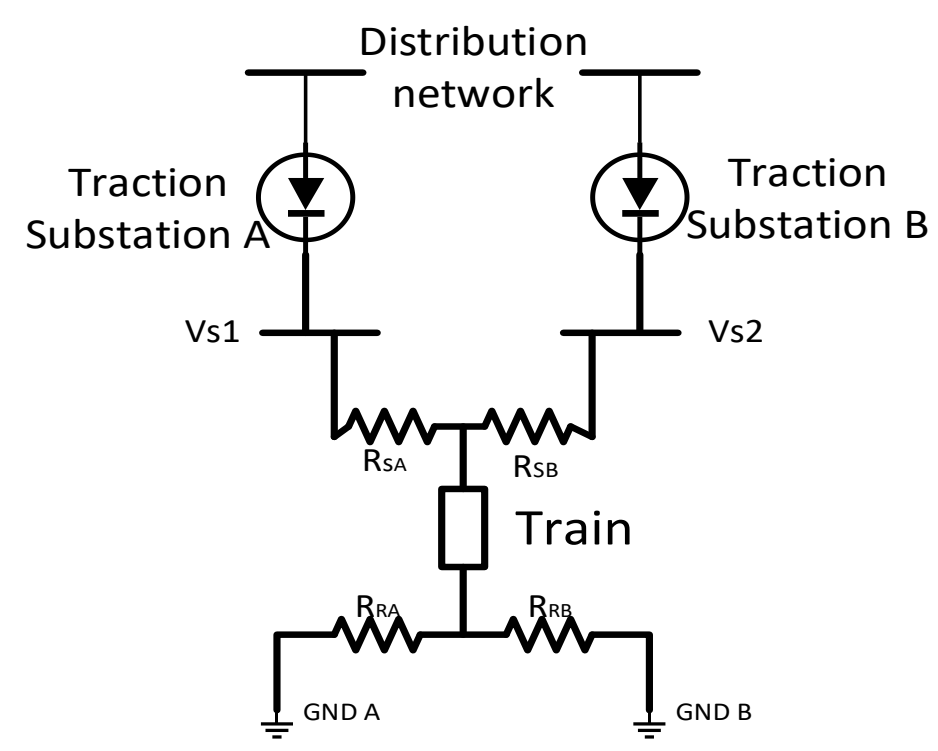

Fig.8 Simple double end fed section with single vehicle

Power is transmitted from the traction substations to the vehicles through a conductor system, for light rail systems this is usually an overhead line catenary, some metro systems use conductor rails. Energy is dissipated through $\mathrm{I}^{2} \mathrm{R}$ losses in the conductors. Fig. 8 shows a double end fed section, with a single vehicle. Current is supplied from both substations through resistances $R_{s 1}$ and $R_{s 2}$ and returns through $R_{R 1}$ and $R_{R 2}$. The transmission losses in this system can be described by adding the losses in each length of conductor.

$$
P_{\text {supply-loss }}=I_{s 1}^{2} R_{s 1}+I_{s 2}^{2} R_{s 2}+I_{R 1}^{2} R_{R 1}+I_{R 2}^{2} R_{R 2}
$$

This can be generalized for any system and described as the sum of copper losses:

$$
P_{\text {supply loss }}=\sum I_{n}^{2} R_{n}
$$


Where $I_{n}$ is the current and $R_{n}$ is the resistances of sections of the supply system. To consider the energy loss, the power loss is integrated over time. The currents and resistances of each section can be described as functions of time, $I(t)$ and $R_{n}(\mathrm{t})$ respectively.

$$
E_{\text {supply loss }}=\int_{0}^{t}\left(\sum I_{n}^{2}(t) R_{n}(t)\right) d t
$$

\section{Case Study: Addis Ababa light rail transit system}

The analysis described in this research paper can be applied to the city of Addis Ababa light rail system to determine the distribution of energy dissipation. Energy consumption of the light rail transit must be analyzed over a complete drive cycle as shown in Fig 9 . The drive cycle covers one kilometer.

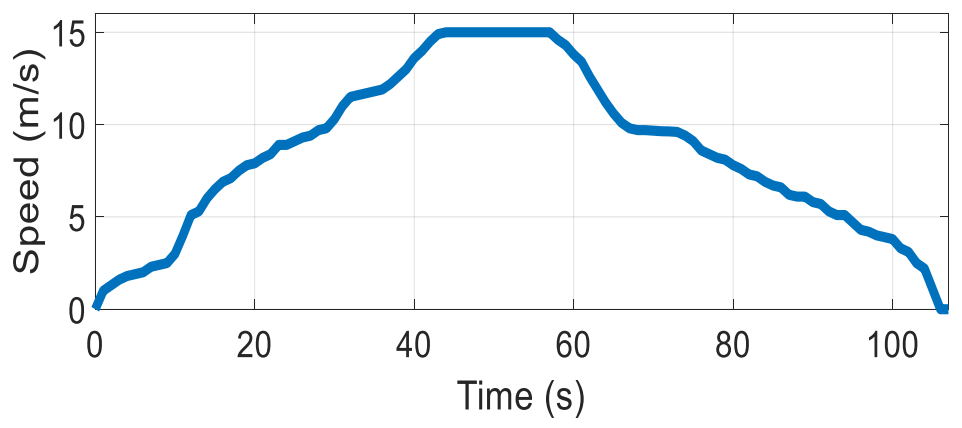

Fig.8 Speed profile

The Power dissipated overcoming frictional forces is calculated using equation (25). The case study is based on Addis Ababa light rail transit and so the frictional parameters of the light rail can be approximated to those of electric motor train of Addis Ababa.

\section{1 frictional losses}

Davis relates the frictional forces for an electric motor train resistance, $F_{R}$ to the train mass, $m$ (in $\mathrm{kg}$ ), number of axles, $n$ (in ton), frontal area in $\mathrm{A}$ (in $\mathrm{m} / \mathrm{s}$ ) and the speed $v$ (in $\mathrm{m} / \mathrm{s})$.

$$
F_{R}=0.933 \sqrt{m n}+12700 \frac{n}{m}+0.000881 m v+0.575 \mathrm{~A} v^{2}
$$

Taking parameters of the Addis Ababa light rail transit, Table 1, the coefficients of the Davis equation can be determined; $a=$ $515.53, b=38.76$ and $c=5.75$. 


\begin{tabular}{|c|c|}
\hline Mass, $\mathrm{m}$ & $44,000 \mathrm{Kg}$ \\
\hline Axle, $\mathrm{n}$ & 6 \\
\hline Frontal area, $\mathrm{A}$ & $10 \mathrm{~m}^{2}$ \\
\hline
\end{tabular}

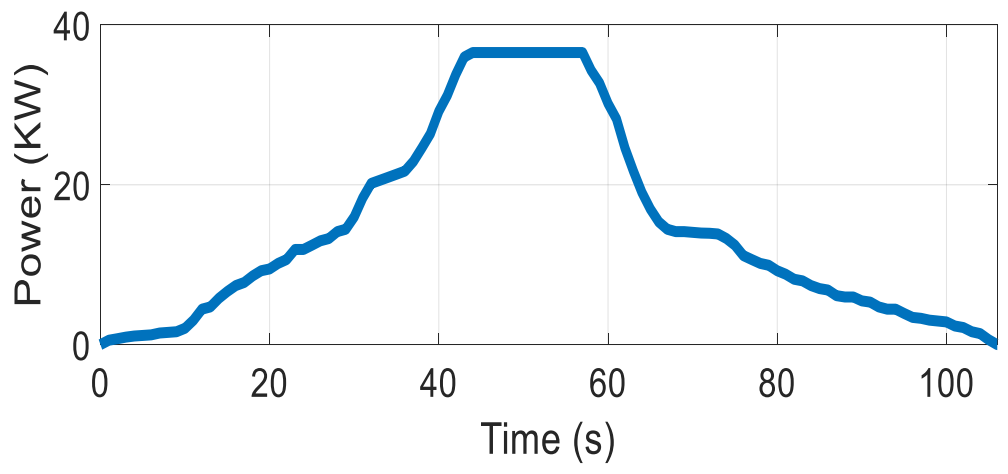

Fig.9 frictional loss over a simple cycle

Fig. 10 shows the friction power profile over the simple drive cycle. Over the drive cycle $1560 \mathrm{~kJ}$ are dissipated through frictional forces.

\subsection{Mechanical Transmission Losses}

Gear box losses can be determined by using equation (26),

$$
P_{\text {gear_loss }}=P_{\text {mechanical }}\left[\frac{f^{\prime}}{2}\left(\beta_{a 1}^{2}+\beta_{r 1}^{2}\right)\right]
$$

To determine this, the mechanical power, $P_{\text {mechanical }}$ is required. The mechanical power is the power required to overcome friction and accelerate the vehicle, it is assumed that the vehicle travels on a level track, and hence no energy is required to climb a gradient.

$$
P_{\text {mechanical }}=P_{R}+P_{\text {acceleration }}
$$

Friction is calculated in the previous section as shown in section 3.1. The power to accelerate the tram can be calculated from equations of motion. 


$$
P_{\text {acceleration }}=m V * a
$$

Where $\mathrm{m}$ is the equivalent mass, which is the sum of the vehicle mass and the equivalent mass of the vehicle rotational parts. The mechanical power for the complete drive cycle is shown in Fig.11.

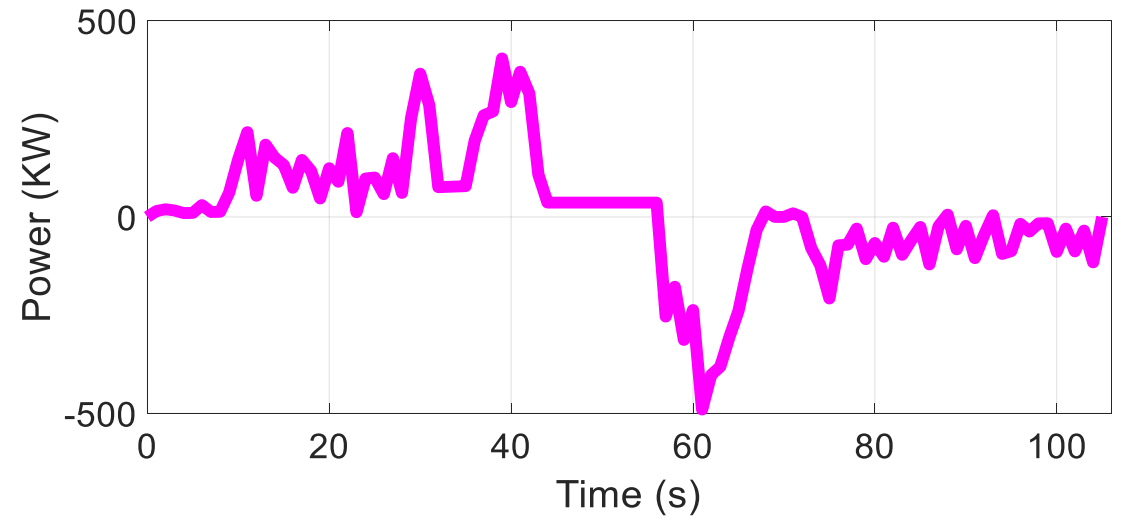

Fig.10 Mechanical power of a single train

The coefficients can be taken from [11] as $f^{\prime}=0.0272, \beta_{a 1}=0.3691$ rads and $\beta_{r 1}=0.3045$ rads. The total energy dissipated through the gears is 35.56 kJ. The energy loss profile is shown in Fig.12.

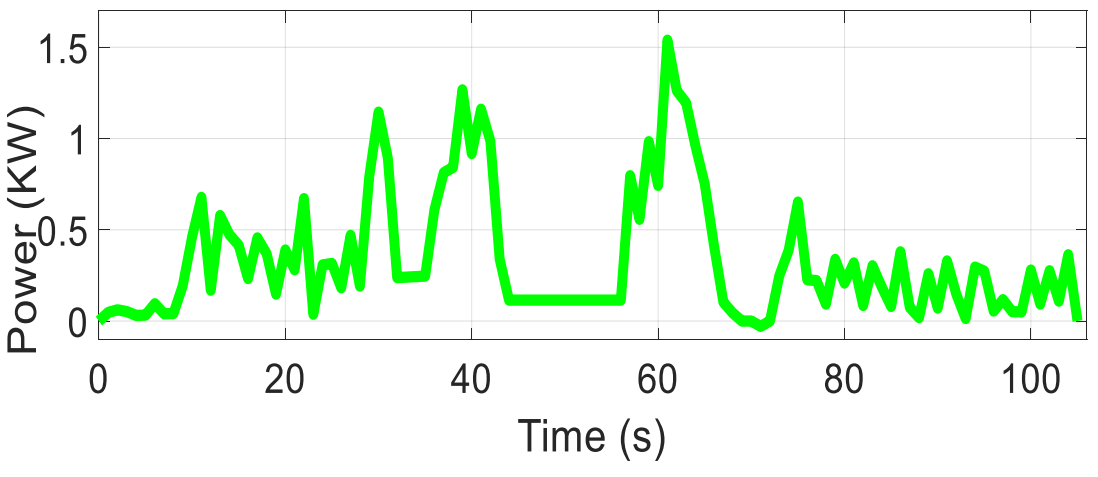

Fig.11 Power dissipated in the gears

The energy dissipated through the gears is small, and so for the purpose of analysis is added to the frictional losses.

\subsection{Induction Motor}


The induction motor losses can be divided into three categories; ohmic losses, iron losses, frictional and windage losses. Frictional and windage losses are considered as frictional losses of the vehicle. An induction motor can be described as an equivalent circuit as shown in Fig.6. Where Xr' and Rr' are equivalent values.

The power dissipated in $R_{r}^{\prime}(1-s) / s$ represents the mechanical power generated by the induction motor, $P_{\text {mechanical }}$.

$$
P_{\text {mechanical }}=I_{1}^{2} R_{r}^{\prime} \frac{(1-s)}{s}
$$

The mechanical power is equal to the sum of the tram mechanical power and the mechanical transmission loss. The power losses in the induction motor can be determined by evaluating the equivalent circuit represented in Fig. 6 . The powers dissipated in the resistances represent the power losses. To determine the power dissipated in the stator and rotor windings, the voltage and frequency of the supply are required. VVVF supply inverters produce a variable voltage variable frequency supply and the voltage is proportional to the frequency.

The equivalent circuit can be solved to determine the losses in each component. The equivalent circuit cannot be solved analytically to determine the required supply voltage and frequency, and therefore the equivalent circuit should be solved numerically, using iterative steps to determine the required voltage and frequency. When the supply voltage and frequency have been determined numerically, the equivalent circuit can be solved to calculate the powers dissipated in each of the equivalent circuit resistors. For a given rotational speed, the motor will have a torque profile depending on the applied frequency and voltage. The torque at a given frequency can be calculated by evaluating the equivalent circuit. The input voltage is proportional to the frequency. The torque can be determined by finding the power dissipated through $R_{r}^{\prime}(1-s) / s$ of the equivalent circuit. The rotor circuit can be evaluated by substituting the supply, stator circuit and iron circuit with a thevenin equivalent supply, Fig. 13.

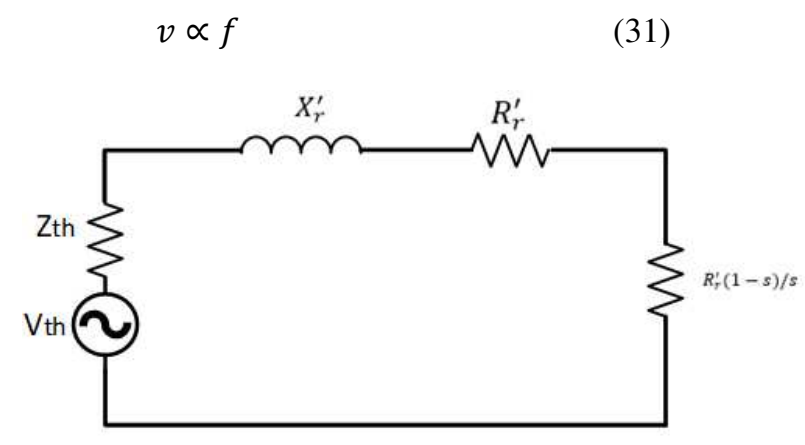

Fig. 13 Rotor circuit with a thevenin equivalent source 
The parameters of the thevenin equivalent voltage and impedance can be calculated using equations (32) and (33).

$$
\begin{gathered}
v_{t h}=v_{M} \frac{\sqrt{x_{m}^{2}+x_{c}{ }^{2}}}{\sqrt{R_{m}^{2}+\left(x_{s}+x_{r}\right)^{2}}} \\
Z_{t h}=R_{t h}+j X_{t h}=\frac{j X_{m}\left(R_{S}+j X_{S}\right)}{R_{S}+j\left(X_{S}+X_{m}\right)}
\end{gathered}
$$

The torque $T_{M}$ produced can be calculated using equation (34)

$$
T_{M}=\frac{3}{\omega_{s y n c}} \frac{v_{t h} \frac{R_{r}}{s}}{\left(R_{t h}+\frac{R_{r}}{s}\right)^{2}+\left(X_{t h}+X_{r}\right)^{2}}
$$

Fig. 14 shows a motor torque profile at a given rotational speed. The applied motor frequency must lie within the stable region, and hence the minimum and maximum torques should be determined. The minimum and maximum can be determined by sweeping through the frequencies and calculating the torque each time: the point at which torque is at a minimum represents the minimum supply frequency and likewise for the maximum obtainable torque, the solution must lie between these values, Fig.14.

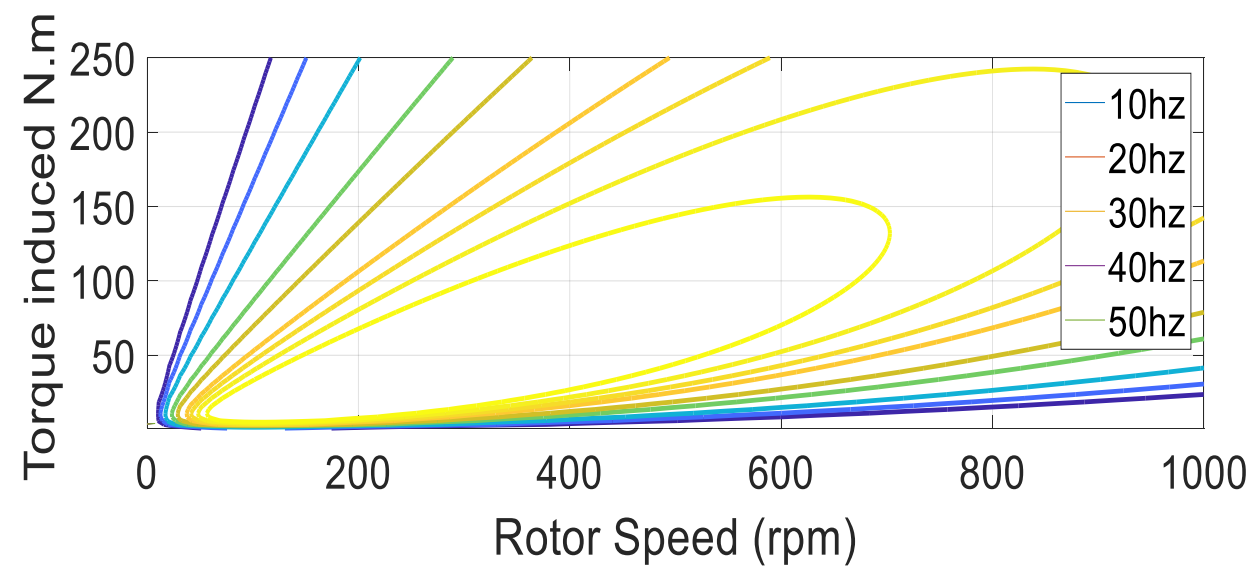

Fig.14 Motor torque profile at 78.5rad/s [17]

When the minimum and maximum motor supply frequencies are determined, the induction motor can be solved using numerical methods. The bisection method, converges to a solution with a minimal error within a few steps. At each step, equations (32), (33) and (34) are evaluated and the torque is determined. The process is repeated using the bisection rule until the difference between the calculated torque and the required torque, the error, decreases to an acceptable level. 
When the supply frequency, and therefore the supply voltage has been determined, the equivalent circuit is solved to find the power dissipated in the stator resistor, rotor resistor and core loss resistor to determine the stator copper loss, the rotor copper loss and the iron core loss respectively. Addis Ababa light rail transit uses four $130 \mathrm{KW}$ motor. Table 2 shows the motor parameters.

Table 2. $130 \mathrm{KW}$ motor parameters [18]

\begin{tabular}{|c|c|}
\hline Parameters & Values \\
\hline Stator inductance & $0.3121 \mathrm{mH}$ \\
\hline Rotor inductance & $0.3121 \mathrm{mH}$ \\
\hline Stator resistance & $0.0351 \Omega$ \\
\hline Rotor resistance & $0.0211 \Omega$ \\
\hline Magnetizing inductance & $1.2 \mathrm{mH}$ \\
\hline Core loss resistance & $215 \Omega$ \\
\hline
\end{tabular}

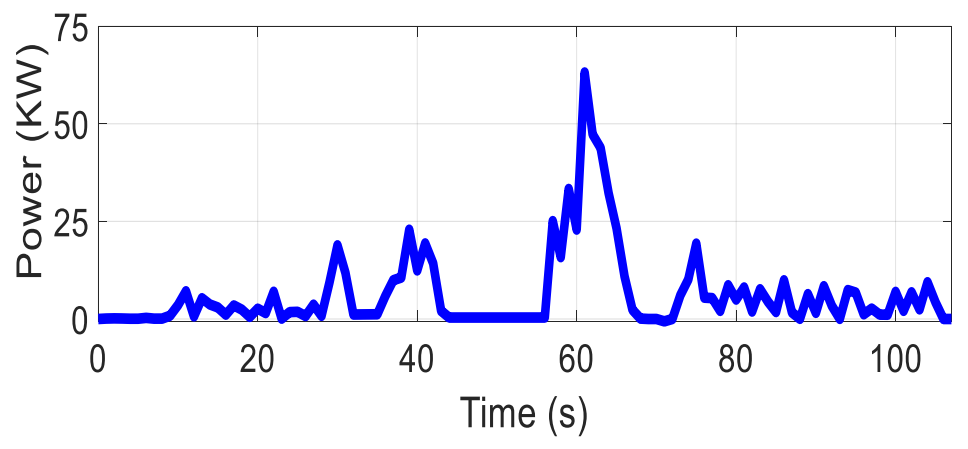

Fig. 15 Motor losses

The total energy dissipated by each induction motor over the simple drive cycle is $300 \mathrm{~kJ}$. This gives $1200 \mathrm{~kJ}$ for the two induction motors. Fig. 15 shows the total motor loss profile for the vehicle.

\subsection{Power Electronic Converter}

The induction motor is driven by an inverter. An inverter consists of six IGBTs with antiparallel diodes. Inverter losses can be divided into two categories, conduction losses and switching losses. The conduction loss of an inverter is dependent on the motor current and whether the diode or IGBT is conducting,

$$
P_{\text {cond_D }}=\frac{1}{T} \int_{0}^{T} V_{F}(t) i_{D}(t) d t
$$




$$
P_{\text {cond_Q }}=\frac{1}{T} \int_{0}^{T} V_{C E}(t) i_{F}(t) d t
$$

The values of $V_{F}(t)$ and $V_{C E}(t)$ are similar, 2.3V and 2.4 $\mathrm{V}$ respectively [8]. This means the conduction losses are similar, and so the analysis can be simplified by assuming all the current is conducted by the IGBTs. The conduction loss can be described as a function of the motor current, $I_{M}$

$$
P_{\text {cond }}=V_{C E O} I_{M}+R_{C E} I_{M}^{2}
$$

Where $V_{C E O}=1.83 \mathrm{~V}$ and $R_{C E}=17.73 \mathrm{~m} \Omega$. The switching losses depend on the switching frequency, equation (38).

$$
P_{\text {switching }} \approx f_{\text {switching }}\left(E_{\text {On }}+E_{\text {OFF }}\right)
$$

The switch on and switch off losses $E_{O n}$ and $E_{O F F}$ respectively are functions of current and can be obtained analytically. They are normally displayed graphically on component datasheets. The relationship can be approximated to a linear relationship,

$$
P_{\text {switching }} \approx f_{\text {switching }} a I_{m}
$$

Where $a$ is a constant, for the Siemens devices this is calculated to be $3 \times 10^{-4} \mathrm{~V}$. The total loss for the inverter can be described as a function of current.

$$
P_{\text {inverter-leg-losses }}=V_{C E O} I_{M}+R_{C E} I_{M}^{2}+f_{\text {switching }} a I_{M}
$$

Taking a switching frequency of $20 \mathrm{kHz}$ and a DC link Voltage of $590 \mathrm{~V}$, the total energy dissipated in each inverter is calculated to be $145 \mathrm{~kJ}$. The power electronics driving the motor has a total energy dissipation of $580 \mathrm{~kJ}$; Fig. 16 shows the power dissipation profile for the power electronics on the vehicle.

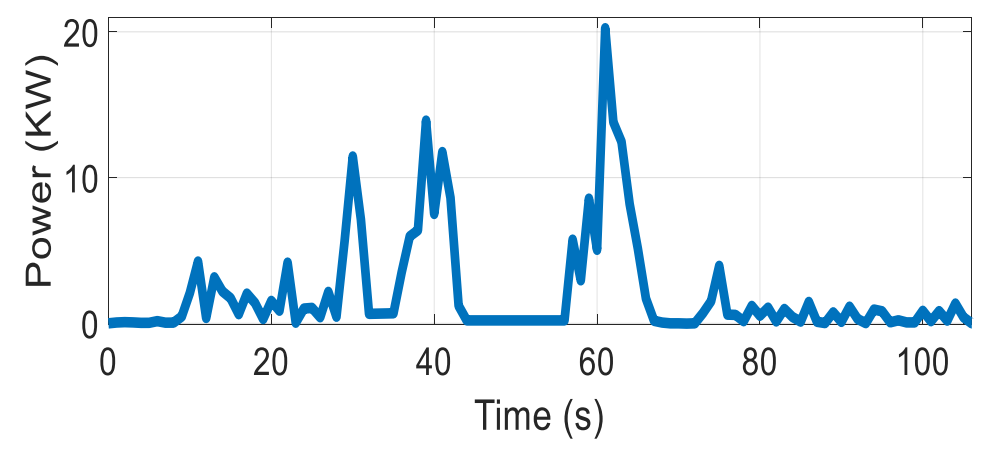

Fig. 16 Vehicle Power Electronics Power Dissipation profile

\subsection{Auxiliary Load}


The auxiliary load for the City Class tram is assumed constant; measurements have indicated that the average auxiliary load is 20 KW.

Over the drive cycle, $2000 \mathrm{~kJ}$ of energy is consumed by the auxiliary loads.

\subsection{Traction Supply System Losses}

The traction supply losses can be determined by solving the traction supply network.

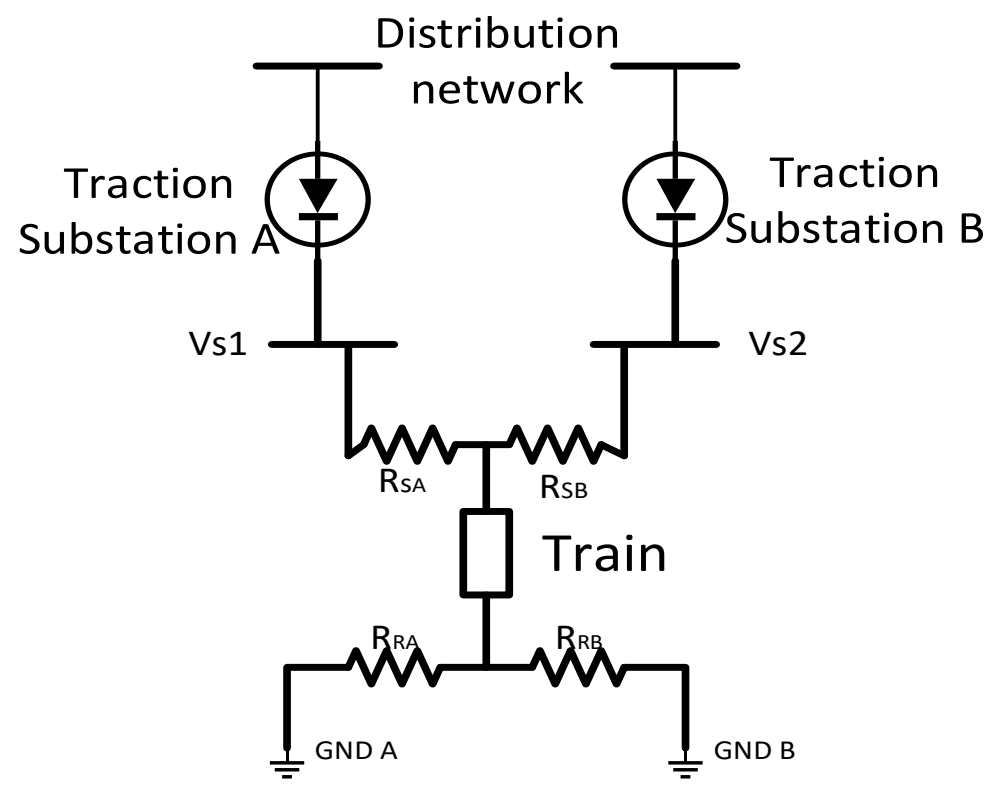

Fig. 17 Electrical circuit for a double end fed section of an electrified transit system

The network impedances are dependent on the position of the vehicle, as the lengths of conductors vary, and hence the parameters of the electrical network vary with time. The losses in the electrical network depend on the total currents, and hence are dependent on all vehicles in the system. Full analysis of system losses should consider all vehicles.

To perform an assessment for a single tram a double end fed section is considered, fig. 17. The section is $1 \mathrm{~km}$ long. For the analysis, the train starts in the middle of the section and finishes at the end. The values of the lumped resistances are calculated from the resistance per unit length and the lengths determined from the position of the vehicle. Values of $0.123 \Omega / \mathrm{km}$ and $0.0924 \Omega / \mathrm{km}$ are used for the resistance per unit length of the supply and return conductors respectively [19]. By applying nodal voltage analysis to the system the currents in each section of conductor can be determined. The losses can be determined and summed to find the total transmission loss. 


$$
P_{\text {supply loss }}=\sum I_{n}^{2} R_{n}
$$

Fig.18 shows the power loss dissipation profile for the traction supply system, 124. kJ of energy are dissipated in the supply system conductors.

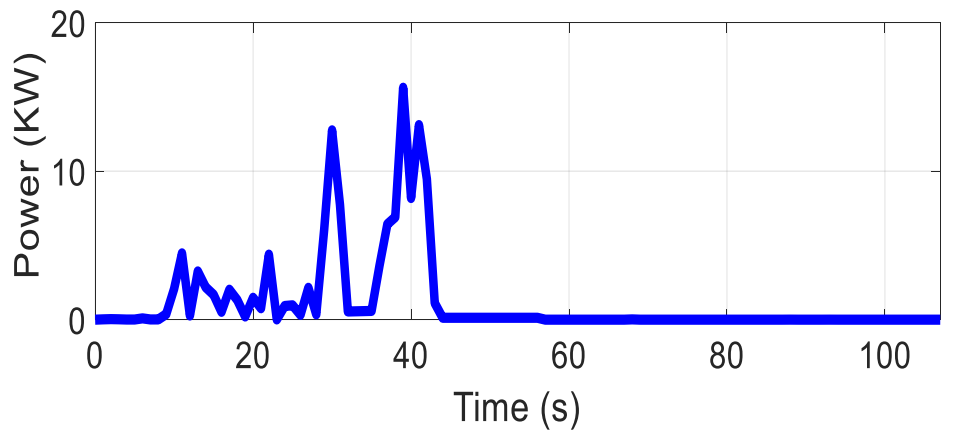

Fig. 18 Traction Supply System Losses

The analysis of the distribution network is also used to determine the currents drawn from each substation, allowing the substation losses to be calculated. The substation losses can be determined using equation (42).

$P_{\text {loss-sustation }}=I_{\text {substation }}{ }^{2}\left(R_{2 e q_{-\_s u b s t a t i o n}}+4 R_{\text {on }}\right)+4 V_{d} I_{\text {sub_station }}+P_{C}$

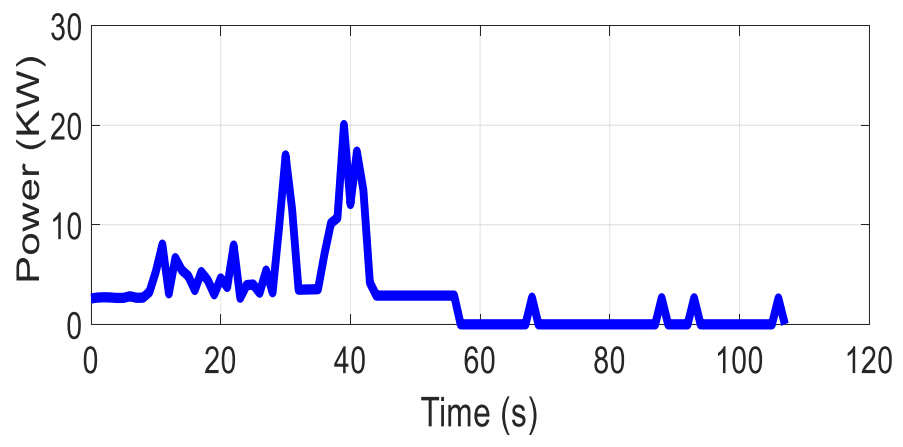

Fig. 19 Traction substation losses

For a $2000 \mathrm{kVA}$ transformer the equivalent resistance $R_{2 \text { 2eq_-substation }}$ of the transformer (on the DC side), is taken as $0.0233 \Omega$ [19]. $R_{\text {on }}$ is the equivalent resistance of the diodes, $V_{d}$ is the forward bias voltage of the diodes. These values were found to be $0.8 \mathrm{~V}$ and $7.7 \mathrm{~m} \Omega$ respectively [8]. No load power, the core losses for a $2000 \mathrm{kVA}, 2.6 \mathrm{~kW}$. The substation losses are approximated to be $460 \mathrm{KJ}$ as shown in fig 19. 


\subsection{Braking Resistor Dissipation}

During braking, kinetic energy of the vehicle is transferred through the vehicle driveline, the remaining energy is dissipated through braking resistors. The total energy dissipated during the simple drive cycle is $3900 \mathrm{~kJ}$; Fig.20 shows the braking power profile.

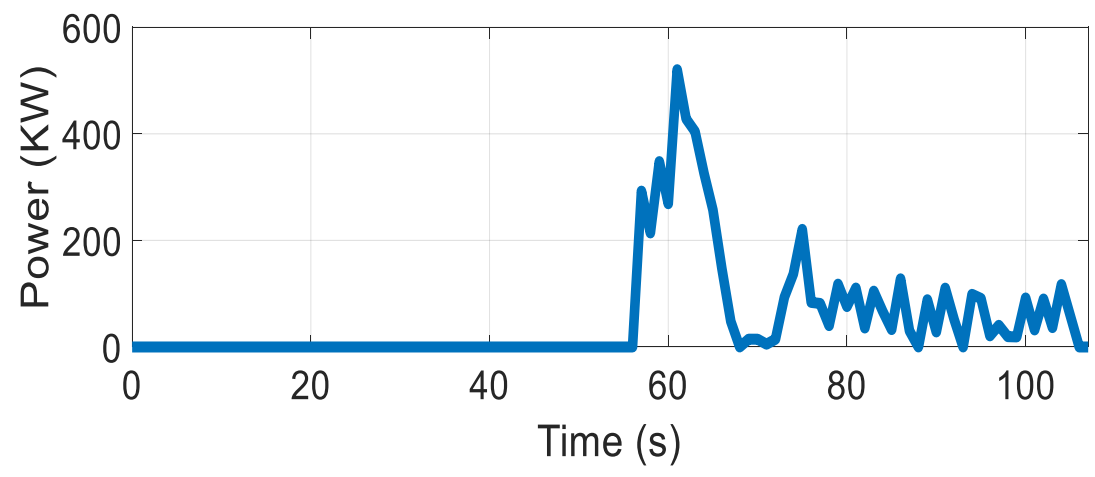

Fig. 19 Power dissipated in braking

\section{Results}

Table 3 shows the distribution of energy dissipation over the simple drive cycle.

\begin{tabular}{|l|c|c|}
\hline Parameters & $\begin{array}{l}\text { Energy } \\
\text { dissipated }\end{array}$ & $\begin{array}{l}\text { Percentage of Energy } \\
\text { dissipated }\end{array}$ \\
\hline Frictional force & $1600 \mathrm{~kJ}$ & $18 \%$ \\
\hline Motor & $1200 \mathrm{KJ}$ & $13.5 \%$ \\
\hline Power electronics & $900 \mathrm{~kJ}$ & $10.1 \%$ \\
\hline Auxiliary Supply & $1500 \mathrm{~kJ}$ & $16.8 \%$ \\
\hline Traction & $124 \mathrm{~kJ}$ & $1.39 \%$ \\
System Losses & & \\
\hline Traction Substation & $460 \mathrm{KJ}$ & $5.1 \%$ \\
\hline Braking energy & $3100 \mathrm{KJ}$ & $36 \%$ \\
\hline
\end{tabular}

The results show the energy dissipated for a simple a complete drive cycle. Table 3 shows the breakdown of energy consumption over this drive cycle. The breakdown only considers the vehicle losses. Based on the analysis is observed that nearly $40 \%$ of total energy 
dissipates on braking resistor and this tells us that a great deal energy could be saved if energy storing devices were applied on Addis Ababa light rail system.

\section{Conclusions}

This paper has presented a detailed methodology for analyzing energy flows in a traction system for Addis Ababa light rail transit. The analysis is used to determine the energy dissipated in each component of an electrified transit system. Application of the analysis to the Addis Ababa light rail transit system revealed that $36 \%$ of energy used in an electrified traction system is dissipated in braking. This emphasizes the potential of installing energy storage on an electric traction system. The analytical tools described form a good basis to construct a model, which could be used to simulate electrified transit systems. This could be used to determine the potential benefits of energy storage.

\section{Reference}

[1] European Commission, Communication from the Commission to the European Parliament, the Council, the European Economic and Social Committee and the Committee of the Regions. (2018) Energy Roadmap 2050 (Last accessed: 23/01/2020). [Online]. Available: http: //ec.europa.eu/energy/energy2020/roadmap/doc/com 20188852 en.

[2] Yoomi Kim, Katsuya Tanaka, and Shunji Matsuoka "Environmental and economic effectiveness of the Kyoto Protocol" plos one, USA, July 21, 2020.

[3] "EVENT Evaluation of Energy Efficiency Technologies for Rolling Stock and Train Operation of Railways," Institute for Futures Studies and Technology Assessment, Berlin March 2003.

[4] S. S. Williamson, A. Emadi, and K. Rajashekara, "Comprehensive Efficiency Modeling of Electric Traction Motor Drives for Hybrid Electric Vehicle Propulsion Applications," Vehicular Technology, IEEE Transactions on, vol. 56, pp. 1561-1572, 2007.

[5] Zhongbei Tian, Ning Zhao and Stuart Hillmansen "Traction Power Substation Load Analysis with Various Train Operating Styles and Substation Fault Modes" energies, Switzerland, June 2020.

[6] Kulworawanichpong, T. Multi-train modeling and simulation integrated with traction power supply solver using simplified NewtonRaphson method. J. Mod. Transport. 23, 241-251 (2015).

[7] Bai Baodong and Chen Dezhi, "Inverter IGBT loss analysis and calculation," 2013 IEEE International Conference on Industrial Technology (ICIT), Cape Town, 2013, pp. 563-569.

[8] Siemens Semiconductor Group, "BSM $75 \quad$ GB 120 DN2 Datasheet" [Online]. Available: https://static6.arrow.com/aropdfconversion/26dd3f85945dbe776875a014616b61c5e333cec1/75gb120dn2.accessed February, 2020. 
[9] Bulent Sarlioglu, Understanding Electric Motors and Loss Mechanisms, university of Wisconsin Madison, 2016.

[10] A. Diaz, R. Saltares, C. Rodriguez, R. F. Nunez, E. I. Ortiz-Rivera and J. Gonzalez-Llorente, "Induction motor equivalent circuit for dynamic simulation," 2009 IEEE International Electric Machines and Drives Conference, Miami, FL, 2009, pp. 858-863

[11] E.Buckingham, Analytical Mechanics of Gears: Dover Publications, 1988.

[12] Erik Magni Vinberg, Energy Use in the Operational Cycle of Passenger Rail Vehicles, Master of Science Thesis Stockholm, Sweden 2018

[13] I. Fisher and G. Bolton, "Auxiliary power systems for rolling stock," in IEE Eighth Residential Course on Electric Traction Systems, 11-15 Oct. 2004, Manchester, UK, 2004.

[14] Asegid B and Getachew B. A research on regenerative braking energy recovery: a case of Addis Ababa light rail transit, IET Electrical Systems in Transportation, 25 March 2020

[15] S. Mousavi, M. Shamei, A. Siadatan, F. Nabizadeh and S. H. Mirimani, "Calculation of Power Transformer Losses by Finite Element Method," 2018 IEEE Electrical Power and Energy Conference (EPEC), Toronto, ON, 2018, pp. 1-5,

[16] China Railway Group (CRECG), Technical Specifications of Vehicles for Addis Ababa light rail transit, internal document, 2011.

[17] Martyn Chymera, the implementation of an energy storage system on-board a light rail traction vehicle, PhD thesis, School of Electrical and Electronic Engineering, john Rylands University, 2019.

[18] China Railways SS1, Ethiopian light rail transit traction motor detail specification, internal document, 2015.

[19] Asegid Kebede; Shimelis Atile ; Demisu Legese, Harmonic Analysis of Traction Power Supply System: Case Study of Addis Ababa Light Rail Transit, IET Electrical Systems in Transportation, 25 March 2020 